\title{
Glenoid Labral Tear: Follow up case series on ultrasound guided autologous platelet rich plasma in conjunction with a progressive rehabilitation program [ $\mathrm{v} 1$; ref status: approved 1, approved with reservations 1, not approved 1 , http://f1000r.es/WqpHu9]
}

\author{
Robert Vander Kraats B. Phty, Post Grad Cert (Sports Physio), Cert \\ (Integrative Medicine) $)^{1}$ Arockia Doss MBBS, MRCP (UK), FRCR, FRANZCR ${ }^{2}$
}

\footnotetext{
${ }^{1}$ Next Generation Physiotherapy, 291 Warwick Road, Greenwood, Western Australia 6024

${ }^{2}$ Image Guided Therapy Clinic, Suite 3, 55 Hampden Road, Nedlands, Western Australia 6009
}

Correspondence to: Robert Vander Kraats: info@ nextgenerationphysiotherapy.com, www.nextgenerationphysiotherapy.com; Arockia Doss: info @imageguidedtherapyclinic.com, www.imageguidedtherapyclinic.com

V1 First published:19 December 2012, 1:68 (doi: 10.3410/f1000research.1-68.v1)

(C) Usage Licensed by Creative Commons CC-BY 3.0

\begin{abstract}
How to cite this article: Vander Kraats R, Doss A (2012) Glenoid Labral Tear: Follow up case series on ultrasound guided autologous platelet rich plasma in conjunction with a progressive rehabilitation program [v1; ref status: approved 1, approved with reservations 1, not approved 1 , http://f1000r.es/WqpHu9] F1000Research 1:68

(doi: 10.3410/f1000research.1-68.v1)
\end{abstract}

\begin{abstract}
Background: Labral tears commonly occur in both the general and sporting population, often leading to significant pain and dysfunction. Patients often engage in progressive rehabilitative programs, and surgical intervention may be required in severe cases. Autologous platelet rich plasma (PRP) injections have been growing in popularity in musculoskeletal medicine as an alternative to corticosteroid injections. This paper looks at the effectiveness of PRP injections in glenoid labral lesions.

Methods: The clinical and radiological findings are presented for two patients who have been treated with autologous PRP into the glenohumeral joint adjacent to the labral tear, in conjunction with a progressive rehabilitative program. Follow up occurred at 18 months and 13 months, respectively.

Results: Both subjects tolerated the PRP injection well with no adverse effects, and were compliant with their rehabilitative programs. On initial presentation, pain on the visual analogue scale (VAS) was $7 / 10$ and $6 / 10$ and at follow up it was reported as $0 / 10$. Both subjects have now returned to normal sporting and work activities.

Conclusions: The findings from this case series suggest that PRP in conjunction with appropriate rehabilitation can assist in the clinical recovery of glenoid labral tears. Further research is required with greater sample numbers and improved methodological parameters.
\end{abstract}

\section{Introduction}

Glenoid labral lesions can often lead to significant discomfort and restriction during daily living activities, as well as various sporting activities. Prevalence can vary between $6 \%$ in the general population ${ }^{1}$ to $35 \%$ in the sporting population ${ }^{2}$. Typical management can range from exercise therapy to surgical intervention. This case report describes the use of ultrasound-guided autologous PRP into the glenohumeral joint adjacent to the labral lesion in two patients, in conjunction with a supervised exercise program.

Case I

In June 2011, an otherwise fit and healthy, right arm dominant 27-year-old male electrician was referred for physiotherapy management to the author. He presented with right intermittent deep shoulder ache occurring one month prior when performing 
multiple supine bench presses in the gym. The patient reported an immediate onset of deep pain distributed around the shoulder region more so posteriorly with an associated 'click'. There was no pain or discomfort described below the deltoid or associated neck pain or headaches. Grip strength was maintained and any activity above ninety degrees of flexion or abduction was ceased secondary to pain levels increasing. All upper limb gym activities were ceased and sleeping on the right side was avoided due to pain. There was no other relevant medical history reported. The patient was able to continue with work, though he avoided provocative movements and lifting. He took $4 \mathrm{~g}$ of paracetamol and $100 \mathrm{mg}$ of Voltaren Rapid daily for pain relief for the initial 2 weeks.

Initial observation on standing revealed an increase in right upper trapezius bulk with normal resting position of the scapulae. Active abduction was limited by pain to $110^{\circ}$, and hand behind head manoeuvre was provocative. External rotation at $90^{\circ}$ was limited by pain to $45 \%$ of range and horizontal flexion was mildly painful. Scapular stabilisation in conjunction with active movement resulted in no change to clinical symptoms. The Obrien's Test was positive (Sen $90 \%$, Spec 98\%3), as was the Crank Test (Sen 80\%, Spec 20\% ${ }^{4}$ ). The Biceps Load Test II was positive (Sen 90\%, Spec
97\% $0^{5}$ ). The Empty Can Test was positive (Sen 62\%, Spec 54\% ${ }^{6}$ ), the Hornblower's Test (Sen 100\%, Spec 93\% ${ }^{7}$ ) and the Speeds Test (Sen $90 \%$, Spec $14 \%^{8}$ ) were positive and posterior glenohumeral joint palpation resulted in pain being reproduced.

On sitting, the cervical spine was cleared and there was no glenohumeral sulcus sign present. The Shift and Load Test [Sen $90 \%$, Spec $85 \%{ }^{9}$ ) was negative and there was adequate thoracic spine mobility. In the supine position, the apprehension test was positive and the acromioclavicular joint was tender. Pectoralis minor was shortened and neural integrity and neurodynamics tests were negative. In the prone position, static scapular setting was adequate, although there was a loss of control with dynamic movements.

The patient agreed to commence a specific rehabilitation program for six weeks in an attempt to improve function and his pain score. The exercise regime consisted of static and dynamic scapular stabilisation in both the prone and sitting positions. Through range scapulohumeral kinematics were addressed with the aid of Theraband. Rotator cuff strength exercises were commenced with a bias on the supraspinatus and teres minor a

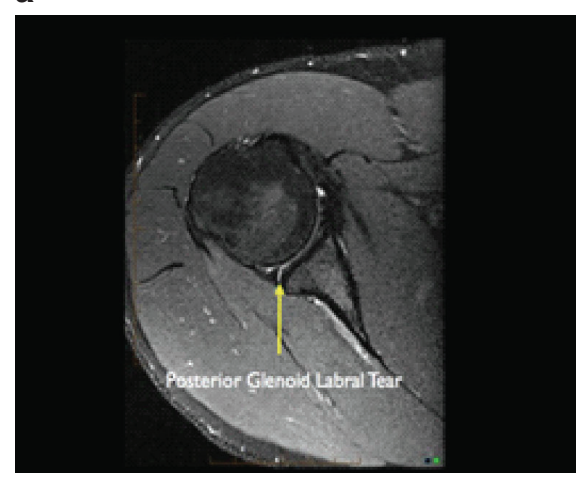

d

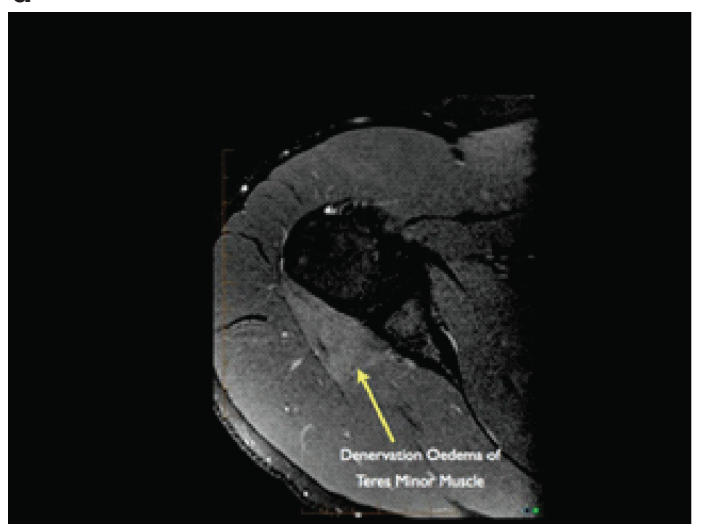

b

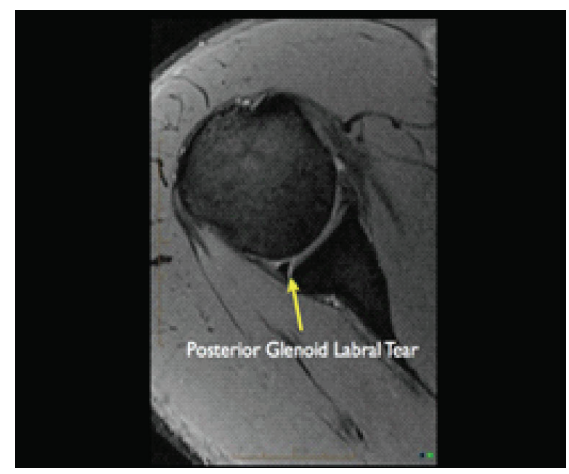

C

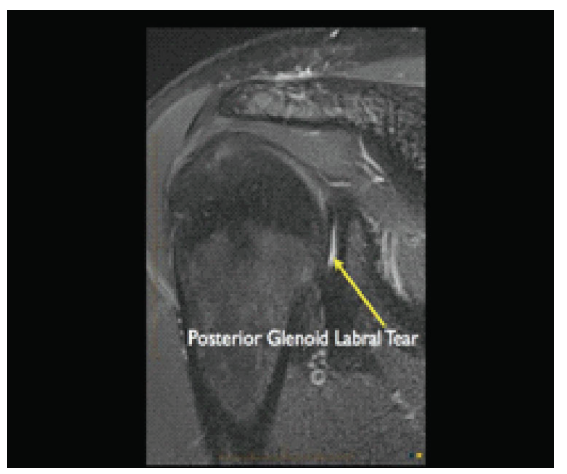

e

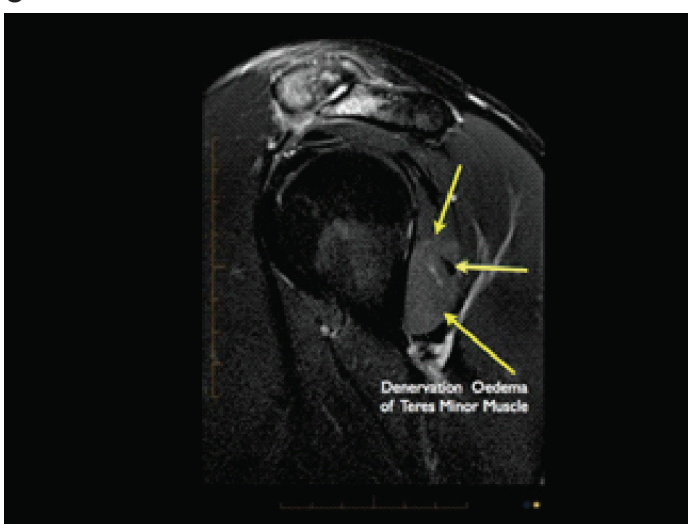

Figure 1 (a) axial T2 fat saturated, (b) axial T2 gradient echo and (c) coronal T2 fat saturated images show the undisplaced posterior labral tear, (d) axial T2 fat saturated and (e) sagittal T2 Fat saturated images shows denervation oedema of teres minor compatible with a brachial neuritis or post traumatic injury. 
muscle groups, in conjunction with subscapularis training to assist in improving the glenohumeral mechanics. A pectoralis minor lengthening exercise was given and general advice regarding good posture was discussed. All the exercises were to be done in a pain free fashion. Real time ultrasound (RTUS) was used throughout the six-week rehabilitation program to ensure that the correct muscle activation pattern was occurring.

After the six-week progressive exercise program, the patient was reassessed functionally and clinical tests were repeated. The patient reported a $70 \%$ improvement in pain scores on the VAS and an increase functional ability. Overhead activities were still unable to be performed secondary to pain and his Obrien's Test, Crank Test and Biceps Load Test II were all positive. The patient reported a decrease in symptom reproduction when the Empty Can Test and Hornblower's Test were performed; however, a positive test was recorded.

The patient was subsequently referred for Magnetic Resonance Imaging (MRI) which showed a $4 \mathrm{~mm} \times 5 \mathrm{~mm}$ delamination split of the supraspinatus tendon and an undisplaced posterior labral avulsion extending craniocaudally for $3.2 \mathrm{~cm}$ superior to inferior quadrant. The long head of biceps tendon is enlocated within the interbercular groove and there was post traumatic degeneration of the right acromioclavicular joint.

The results were discussed with the patient with the assistance of the MRI imaging and a model of the shoulder joint. An orthopaedic consult was suggested, but the patient declined as he did not want to go down the surgical treatment pathway. The option of autologous PRP into the paralabral region and glenohumeral joint was discussed on the basis of autologous product with anti-inflammatory properties that may enable an analgesic effect. The patient was made aware that there had been no published evidence, no high level research into such procedure being performed in the shoulder, possible complications and no guaranteed outcomes. He requested the treatment and gave full informed consent. Under ultrasound guidance using a strict aseptic technique, $5 \mathrm{cc}$ of $0.5 \%$ bupivacaine was injected into the paraglenoid soft tissues, followed by $8 \mathrm{cc}$ of autologous PRP (BCT, REGEN Labs, Switzerland) into the glenohumeral synovial cavity near the posterior inferior quadrant of the torn glenoidlabrum with no pain. 2cc of PRP was injected under ultrasound guidance into the acromioclavicular joint. Post injection, the shoulder was placed in a sling for 10 days with elbow ranging allowed.

Two weeks post PRP injection the patient returned for physiotherapy review and reported an improvement in function and pain scores equating to an $85 \%$ improvement on the VAS. The patient could now engage in more functional overhead activities pain free and reported less apprehension. His initial exercise program was recommenced and progressed accordingly to incorporate outer range shoulder movements and to facilitate a return to weight lifting and Muay Thai. At the four-week post PRP review with the radiologist, the patient reported considerable improvement in pain and function of the shoulder and no further injections were needed.

At his 18 month follow up appointment with the physiotherapist, the patient described complete resolution of all symptoms, a return to Muay Thai, and engagement in pre-injury gym training. Clinical tests included the Obrien's, Crank, Biceps Load Test II, Empty Can and the Speeds Test, which were all negative. There were no further clinical symptoms to suggest labral lesion involvement, and repeat imaging was therefore not justified in the clinical setting.

\section{Case II}

In October 2011, an otherwise fit and healthy 25-year-old female receptionist was referred for radiological intervention to the author. She presented with a 7-year history of gradual onset of right shoulder pain after playing several seasons of softball. She described the symptoms as a deep ache in the joint, particularly made worse with overhead activities. She denied any specific injury to her shoulder, and believed several seasons as a right arm pitcher was the cause. She currently had stopped playing softball and avoided any provocative activities.

Prior to initial assessment with the authors, the patient reported she had received several corticosteroid injections over the 7 -year history into her right subacromial bursa, none of which gave her complete relief of her symptoms. In 2009 she had a motor vehicle accident which resulted in a $7 \%$ loss of function to her cervical and lumbar spine. She reported spinal function had since improved greatly to date, though she still gets the occasional frontal headache. Six months prior to presentation, she was advised to focus on strengthening her upper limbs, for which she undertook an aggressive gym program for three months. Subsequently, her shoulder pain flared up significantly, resulting in lack of sleep and reduced function. She stopped all exercise after the flare up.

Her MRI showed a thickened coracoacromial ligament with established subacromial bursitis, a $2 \mathrm{~mm} \times 3 \mathrm{~mm}$ partial tear on the mid supraspinatus tendon and an undisplaced Superior Labral Anterior to Posterior (SLAP) tear at the junction with the long head of biceps tendon without a measurable fragment.

At the first visit for radiological intervention there was marked localising tenderness to the insertion of the trapezius into the spine of the scapula, a positive O'Brien's Test and pain on provocation of the long head of biceps. The posterior shoulder pain was treated with ultrasound guided percutaneous tenotomy and injection of $5 \mathrm{cc}$ of unclotted autologous blood mixed with $3 \mathrm{cc}$ of $0.5 \%$ bupivacaine into the insertion of the trapezius at the medial margin spine of the scapula. At her 4 -week review by the radiologist, pain from the above had remarkably improved. 
a

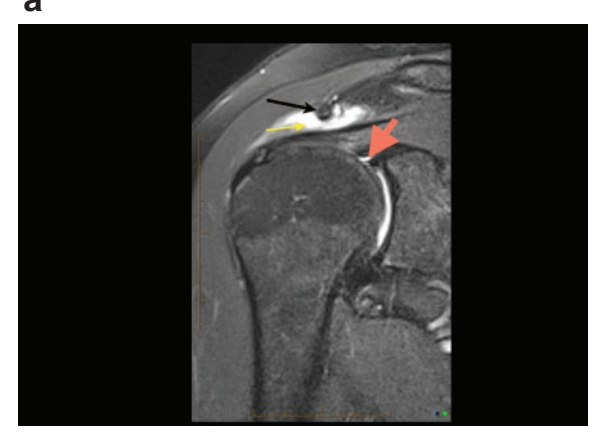

b

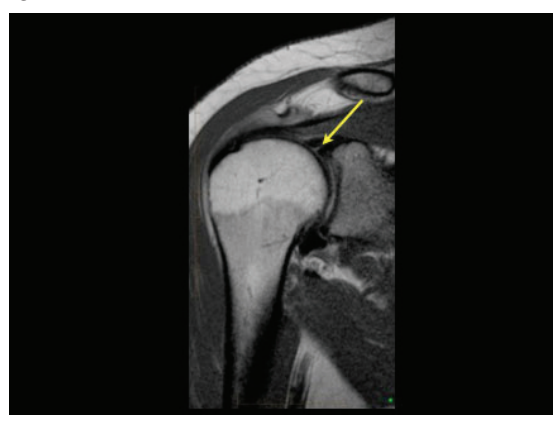

C

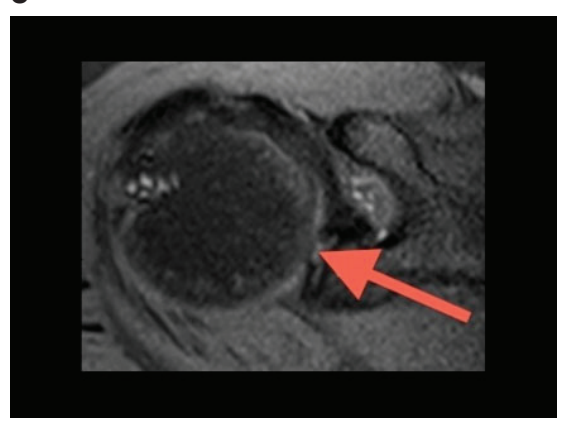

Figure 2 (a) orange arrow in this T2 fat saturated coronal image shows undisplaced tear at the junction of the long head of biceps and superior labrum, this is also seen in (b) yellow arrow in coronal proton density image. Black arrow in (a) shows a thickened coracoacromial ligament and yellow arrow shows subjacent asymptomatic subacromialsubdeltoid bursitis, (c) orange arrow in this axial T2 fat saturation image shows the SLAP tear at the junction of the long head of biceps and superior labrum.

However, she had persisting symptoms that was thought to be originating from the SLAP lesion. She was referred for physiotherapy review for assessment and correction of any abnormal biomechanics, shoulder kinetics and glenohumeral instability.

At her initial physiotherapy review, observation in standing revealed that there was a kyphotic cervical spine resting position with associated protracted scapulae. There was also posterior cuff wasting with compensatory upper trapezius bulk. Active abduction was limited to $100^{\circ}$ by pain and external rotation at $90^{\circ}$ could not be performed due to provocation. Facilitated seated scapular stabilisation in conjunction with active shoulder range of movements resulted in only minor improvement in function. The Obrien's Test, Biceps Load Test II and Crank Test were all positive. The Neers Test was positive as was the Speeds Test and the Empty Can Test. Anterior joint line tenderness was considerable.

On sitting, the cervical quadrant test was negative and there was no tenderness on the acromioclavicular joint. There was no sulcus sign present and the Shift and Load Test was negative. The thoracic spine was hypomobile. In the supine position, the Shoulder Apprehension Test was positive and neural integrity and neurodynamics tests were negative. Prone scapular setting was poor with minimal ability to control upper limb movements with adequate scapular positioning.

Rehabilitation involved spinal posture correction exercises incorporating adequate resting scapulae positions and supraspinatus strengthening exercises with the RTUS. Motor control of subscapulariswas also addressed to ensure correct dynamic movements of the glenohumeral joint complex were achieved.

Six weeks after commencing rehabilitation, the patient reported a $40 \%$ improvement in symptoms but was still unable to complete tasks above shoulder height without any pain. The patient declined the offer of an orthopaedic consult.
At radiological review, her Oxford Shoulder Score was 26, indicating moderate affliction. She consented to a PRP injection with an explanation of the procedure and risks similar to case 1 . Using an aseptic technique, $5 c c$ of $1 \%$ lignocaine and 6cc of PRP mixture (BCT, REGEN Labs, Switzerland) was injected under direct ultrasound visualisation into the glenohumeral synovial cavity through the posterior glenohumeral recess. Immediately post injection there was complete resolution of shoulder symptoms, indicating a positive anaesthetic response, and confirming that the glenohumeral joint was the source of pain. The shoulder was placed in a sling for 10 days and an elbow ranging exercise was given.

Two weeks after the PRP injection the patient reported a 65\% improvement on the VAS, and could now engage in some overhead activities. She continued with her specific rehabilitation with the assistance of the RTUS to ensure accuracy of muscle activation. Six weeks post PRP injection her Obrien's and Crank Test were negative, as was the Speeds Test. Visible muscle hypertrophy was evident through the posterior cuff, which was confirmed on RTUS, and overhead activities could be performed with minimal pain.

At her 13 month follow up, the patient reported that all her symptoms had resolved with adequate functional level to compete in high grade volleyball and to throw a medicine ball above shoulder height at boot camp. There were no further clinical symptoms to suggest labral lesion involvement, and repeat imaging was therefore not justified in the clinical setting.

\section{Discussion}

The glenoidlabrum is a triangular fibrocartilaginous structure that assists in deepening the labrum to provide some mechanical stability for the humeral head. This vulnerable structure can result in labral lesions occurring in both the general and sporting population. There has been extensive research suggesting a link between labral pathology and rotator cuff involvement. Up to $45 \%$ of patients with labral lesions were also found to have 
partial thickness tears of the supraspinatus ${ }^{10}$ as found in both of the reported cases. Therefore, specific rehabilitation that targets rotator cuff deficits in association with glenohumeral positioning is an important part of the recovery process.

The authors recognise the mixed viewpoints in the literature regarding the exact aetiology and pathomechanics of glenoid labral lesions ${ }^{11-13}$. It is therefore paramount that a good subjective history is taken and clinical testing is directly correlated to the symptoms and the imaging findings. The authors also recognise the importance of performing all the clinical tests on the non-symptomatic side to ensure a sound baseline for comparison exists. Although the effectiveness has yet to be validated in shoulder rehabilitation, the use of a RTUS to ensure the correct muscle activation occurs is an extremely useful tool for both patient educational purposes and progression of exercises.

Repair of cartilage and tendon lesions is the holy grail of musculoskeletal medicine. The majority of musculoskeletal disorders are due to degenerative pathologies that result in multifactorial chronic pain. There is chronic imbalance between anabolism and catabolism at a cellular level with an unfavourable microenvironment that results in further destruction of normal structure. The reader is referred to the paper by Chikanza and Fernandes for more information ${ }^{14}$. Inherent catabolic properties and side effects of corticosteroids have resulted in the search for an alternative injectable product for pain relief in these patients. The ideal option would be a non-surgical minimally invasive technique that delivers a product with minimal or no side effects with the ability to restore a favourable microenvironment that allows regeneration of degenerative tissue.

PRP is an autologous agent with a very high concentration of naturally occurring growth factors. It has been in use for at least two decades in maxillofacial surgery and is rapidly gaining popularity in orthopaedic medicine. PRP carries very minimal risks and is distinctly different to cortisone in that it is not a catabolic, with no risk of destruction of normal tissue. PRP has anti-inflammatory properties that inhibit inflammatory processes in osteoarthritic chondrocytes ${ }^{15}$. Labral tissue is fibrocartilage and in an animal model meniscal tear, PRP enhanced repair of meniscal fibrocartilage ${ }^{16}$. PRP has also been shown to play a role in regeneration of degenerative rotator cuff tears by enhancing proliferation and matrix synthesis of tenocytes ${ }^{17}$. However, the use of PRP has had unfavourable review, as seen by recent studies in rotator cuff tears. Two randomized controlled trials, one with 79 patients and the other with 88 patients comparing PRP fibrin matrix (PRFM) versus control on rotator cuff tendon healing showed no demonstrable differences on tendon healing and clinical rating scales ${ }^{18,19}$. Bergeson $e t$ al. also showed similar results with PRFM in at-risk rotator cuff tears ${ }^{20}$. This may reflect several factors, including differences in individual products of PRP preparation. These studies used a semisolid implant material that had to be delivered through the arthroscope cannula, which is quite different to injectable liquid PRP preparations. This implant was left at the bone tendon interface and may have resulted in a space occupying effect, in addition to an unfavourable biological milieu with increased inflammatory mediators. In a laboratory model, human PRP has been shown to stimulate migration and chondrogenic differentiation of human subchondral progenitor cells ${ }^{21}$. Glenohumeral intra-articular injection of PRP with the aim of stabilising fibrocartilage and hyaline cartilage lesions has evolved subsequent to safety and efficacy results of studies with good short-term results in osteoarthritis of the hip and knee joints ${ }^{22,23}$. In the past few years there has been interest in mesenchymal pluripotent stem cells (MSC) in regeneration of cartilage and tendon disorders. Mokbel et al. showed in a dog study that intra-articular injection of MSC is a viable option for treating partial cartilage defects by proving that injected MSC demonstrated homing and incorporation of labelled MSCs in the neocartilage reparative tissue ${ }^{24}$. PRP has also been shown to enhance proliferation of MSCs and chondrogenic differentiation ${ }^{25}$.

In the authors' practices, patients are informed of the option of promoting proliferation of bone marrow stem cells by nutritional supplements through the consumption of blueberries, Vitamin D3 and green tea ${ }^{26}$ as an alternative to harvest and injection of MSCs.

The authors have used PRP in conjunction with optimal biomechanics pre and post PRP injection to ensure the best chances of a favourable outcome. This paper adds to anecdotal evidence on the use of intra-articular PRP in fibrocartilage lesions with favourable clinically significant results. It does not offer a statistically significant result or evidence for routine practice.

\section{Conclusion}

In both case studies, the patients had complete resolution of symptoms, and were able to return to normal activities, including impact sports. This is the first published report on the use of ultrasound guided PRP in conjunction with physiotherapy to treat glenoid labral tears with a favourable outcome. This report offers evidence that PRP with appropriate rehabilitation is a viable, low risk alternative to corticosteroid injections or surgical procedures in glenoid labral tears. Further research is required with larger sample numbers and improved methodological parameters to further validate these findings.

\section{Consent}

Written informed consent for publication of clinical details and clinical images was obtained from both subjects and the radiology company.

\section{Author contributions}

Physiotherapy comments were by the primary author, radiological comments by secondary author. 
Grant information

There was no grant funding.
Competing interests

There was no competing interests.
1. Handelberg, F., Willems, S., Shahabpour, M., Huskin, JP., Kuta, J. SLAP lesions: a retrospective multicentre study. Arthroscopy, 1998; 14: 856-862.

2. Funk, L., Snow, M. SLAP tears of the glenoidlabrum in contact athletes. Clinical Journal of Sports Medicine, 2007; 17 (1): 1-4.

3. O'Brien, SJ., Pagnani, MJ., Fealy, S., McGlynn, SR., Wilson, JB. The active compression test: A new and effective test for diagnosing labral tears and acromioclavicular joint abnormality. American Journal of Sports Medicine, 1998; 26: 610-613.

4. Snyder, SJ, Karzel, RP., Del Pizzo W. SLAP lesions of the shoulder. Arthroscopy, 1990, 6: 274-279.

5. Kim, SH., Ha, Kl., Ahn, JH., Kim, SH., Choi, HJ. Biceps Load Test II: A clinical test for SLAP lesions of the shoulder. Arthroscopy, 2001; 17: 160-164

6. Holtby, R., Razmjou, H. Validity of the Supraspinatus Test as a Single Clinical Test in Diagnosing Patient with Rotator Cuff Pathology. Journal of Orthopaedic and Sports Physical Therapy, 2004; 34:194-200.

7. Walch, G., Boulahia, A., Calderone, S., Robinson, A. The dropping and hornblower's sign in evaluation of rotator cuff tears. The Journal of Bone and Joint Surgery, 1998; 80: 624-8.

8. Bennet, WF. Specificity of the Speed's Test: Arthroscopic technique for evaluating the biceps tendon at the level of the bicipital groove. Arthroscopy, 1998; 14: 789-796.

9. Cleland Journal of Orthopedic Clinical Examination: An Evidence-Based Approach for Physical Therapists. Carlstadt, NJ: Icon Learning Systems; 2005.

10. Andrews, JR., Carson, WG. The arthroscopic treatment of glenoidlabrum tears in the throwing athlete. Orthopaedic Transaction Journal, 1984: 8: 44

11. Andrews, JR., Carson, WG Jr, McLeod, WD. Glenoid labrum tears related to the long head of the biceps. American Journal of Sports Medicine, 1985; 13 (5): 337-41.

12. Burkhart, SS., Morgan, CD. The peel-back mechanism: its role in producing and extending posterior type II SLAP lesions and its effect on SLAP repair rehabilitation. Arthroscopy, 1998; 14 (6): 637-40.

13. Pagnani, MJ., Deng, XH., Warren, RF. Effect of lesions of the superior portion of the glenoid labrum on glenohumeral translation. Journal of Bone and Joint Surgery, 1995; 77 (7): 1003-10.

14. Chikanza, IC., and Fernandes L. Novel strategies for the treatment of osteoarthritis. Expert Opinion on Investigational Drugs, 2000; 9 (7): 1499-1510

15. Van Buul, GM., Koevoet, WL., Kops, N., Bos, PK., Verhaar, JA., Weinans, H., Bernsen, MR., van Osch, GJ. Platelet-rich plasma releasate inhibits inflammatory processes in osteoarthritic chondrocytes. American Journal of Sports Medicine, 2011; 39 (11): 2362-2370.
16. Ishida, K., Kuroda, R., Miwa, M., Tabata, Y., Hokugo, A., Kawamoto, T., Sasaki, K., Doita, M., Kurosaka, M. The regenerative effects of platelet-rich plasma on meniscal cells in vitro and its in vivo application with biodegradable gelatin hydrogel. Tissue Engineering, 2007; 16 (5): 1103-12.

17. Chris HJ. Platelet-Rich Plasma Stimulates Cell Proliferation and Enhances Matrix Gene Expression and Synthesis in Tenocytes From Human Rotator Cuff Tendons With Degenerative Tears. American Journal of Sports Medicine, 2012; 40: 1035-1045.

18. Rodeo, SA., Delos, D., Williams, RJ. The effect of plateletrich fibrin matrix on rotator cuff tendon healing: a prospective, randomized clinical study. American Journal of Sports Medicine, 2012; 40 (6): 1234-41.

19. Castricini, R., Longo, UG., De Benedetto, M. Platelet-rich plasma augmentation for arthroscopic rotator cuff repair: a randomized controlled trial. American Journal of Sports Medicine, 2011; 39 (2): 258-265.

20. Bergeson, AG., Tashjian, RZ., Greis, PE., Crim, J., Stoddard, GJ., Burks, RT. Effects of platelet-rich fibrin matrix on repair integrity of at-risk rotator cuff tears. American Journal of Sports Medicine, 2012; 40 (2): 286-293.

21. Krüger, JP.,Hondke, S., Endres, M., Pruss, A., Siclari, A., Kaps, C. Human platelet-richplasma stimulates migration and chondrogenic differentiation of human subchondral progenitor cells. Journal of Orthopaedic Research, 2012; 30 (6): 845-52.

22. Kon, E., Mandelbaum, B., Buda, R., Filardo, G., Delcogliano, M., Timoncini, A., Fornasari, PM., Giannini, S., Marcacci, M. Platelet-rich plasma intra-articular injection versus hyaluronic acid viscosupplementation as treatments for cartilage pathology: from early degeneration to osteoarthritis. Arthroscopy, 2011; 27 (11): 1490-501.

23. Sanchez, M., Guadilla, J., Fizl, N., Andia, I. Ultrasound-guided platelet-rich plasma injections for the treatment of osteoarthritis of the hip. Rheumatology, 2012; 51 (1): 144-150.

24. Mokbel, A., El-Tookhy, O., Shamaa, AA., Sabry, D., Rashed, L., Mostafa, A. Homing and efficacy of intra-articular injection of autologous mesenchymal stem cells in experimental chondral defects in dogs. Clinical and Experimental Rheumatology, 2011; 29 (2): $275-84$

25. Mishra, A., Tummala, P., King, A., Lee, B., Kraus, M., Tse, V., Jacobs, CR. Buffered platelet-rich plasma enhances mesenchymal stem cell proliferation and chondrogenic differentiation. Tissue Engineering, 2009; 15 (3): 431-5.

26. Bickford, PC., Tan, J., Shytle, RD., Sanberg, CD., El-Badri, N., Sanberg, PR. Nutraceuticals synergistically promote proliferation of human stem cells. Stem Cells and Development, 2006; 15 (1): $118-23$. 


\section{Open Peer Review}

\section{Current Peer Review Status: $\times \checkmark$ ?}

\section{Version 1}

Reviewer Report 09 January 2013

https://doi.org/10.5256/f1000research.403.r653

(C) 2013 Andia I et al. This is an open access peer review report distributed under the terms of the Creative Commons Attribution License, which permits unrestricted use, distribution, and reproduction in any medium, provided the original work is properly cited.

\section{Isabel Andia}

Unidad de Cirugía Astroscópica, Vitoria-Gasteiz (Araba), Spain

\section{Michele Abate}

Department of Medicine and Sciences of Aging, University of G. d'Annunzio, Chieti Scalo, Italy

Isabel Andia, reporting on the PRP aspects of this article,

From the area of my expertise in PRP therapies, I have some reservations:

One of the main questions that remain unanswered regarding the use of PRP is optimal formulation.

Differents types of PRP have been identified in base of platelet enrichment and leukocyte concentration (relative to peripheral blood) and activation procedure. These crucial aspects are not mentioned in this article.

Moreover, the authors dilute (8:5) (PRP:bupivacaine sol.) in the first case and (6:5) (PRP:lignocaine sol.) which raises concerns about their final PRP product and the capability to clot.

I would suggest that the authors describe the formulation of their product and discuss the inconvenience of diluting the PRP product and mixing PRP with anesthetics (Carofino B. Et al., 2012 Corticosteroids and local anesthetics decrease positive effects of platelet-rich plasma: an in vitro study on human tendon cells. Arthroscopy. 711-9.) 


\section{Michele Abate, reporting on the rehabilitation aspects of the article,}

General: The authors should provide the timing of the rehabilitation program before and after PRP injections and have to specify the progression of the exercises.

Case I: Why was MRI performed after the failure of the rehabilitation program and not before? This could have influenced the outcome of the rehabilitation program.

Which stretching exercises were performed? Was it only on the minor pectoralis?

Did the patient perform exercises for impingement syndrome (lowering of the humeral head)?

What about the strengthening of biceps and triceps? How did the patient perform exercises? Was it with the aid of only Theraband, or other specific devices (isokinetic)?

Which suggestions about posture did the author provide?

Case II: In this case, the rehabilitation program was wrong in the first phase. The patients suffered, in addition to SLAP (superior labral anterior to posterior) tear, impingement syndrome with bursitis and partial rotator cuff tear.

This was the reason the patient had scanty results from the rehabilitation. During this period more attention had to be provided in the treatment of cervical spine and its dysfunction and of impingement syndrome. Which active exercises did the patient perform?

Competing Interests: No competing interests were disclosed.

We confirm that we have read this submission and believe that we have an appropriate level of expertise to confirm that it is of an acceptable scientific standard, however we have significant reservations, as outlined above.

Author Response 20 Mar 2013

Robert Vander Kraats, Next Generation Physiotherapy, Greenwood, Australia

Case I: Referring for the MRI when the patient initially presented compared to at the 6 week mark would have made no difference to the rehab outcome. As reported, the patient just with rehab alone reported a 70\% reduction on the VAS and improved functionality at the 6 week mark. The other important aspect here is one should never simply diagnose a musculoskeletal complaint from imaging alone; rather a good physical assessment with sound clinical reasoning by an experienced clinician is essential. Refer to Jenson \& Modic et al. (1994) and Weishaupt \& Boos et al. (1998). Furthermore, Liu et al. (1996) compared physical examination to MRI in assessment of glenoid labral tears confirming that physical 
examination yielded a sensitivity of $90 \%$ and a specificity of $85 \%$, compared to MRI of $59 \%$ and $85 \%$ respectively, when compared to arthroscopy. Throughout the intensive rehabilitation program, importance was placed on improving the scapulothoracic and scapulohumeral rhythm kinematics.

Along with addressing muscular imbalances in the form of length and strength differences comparing anterior to posterior cuff, importance was placed on functional exercises relevant to the patient. In the author's opinion, it is paramount to not get into the habit of prescribing exercises of no relevance to the patient's work or sport for example. Granted in the very early stage this may be acceptable, but certainly this should not be the focus. Doing a basic biceps curl in isolation, as suggested by the reviewer, without any scapulothoracic/ humeral activation or sport specific relevance is unlikely to add favourably to the clinical outcome.

Case II: The patient certainly did not "suffer" due to a "wrong" rehabilitation program after the subject was referred to the author. Despite the chronic nature of the complaint, after just six weeks of intensive rehab the patient reported a $40 \%$ improvement on the VAS. One needs to always consider the mechanics and movement patterns of the cervical spine in a patient with a past history of a significant whiplash injury, particularly when considering scapulohumeral/thoracic dysfunction in a symptomatic labral tear. As such, the cervical rehab focussed extensively on the deep cervical muscles as per Jull et al.'s (2008) comprehensive research.

Furthermore, with the assistance of a bio-feedback pressure sensor to maintain deep cervical muscle control, shoulder kinematics were added from inner range to outer range, progressed to sport specific positions as able. The other important factor to note is the impingement and bursitis were both not the primary source of symptoms. The subject had a normal acromion on Xray and the multiple cortisone injections failed to give relief. Both were simply secondary to altered kinematics between the cervical/thoracic/scapulohumeral mechanism, with an underlying symptomatic labral pathology. Therefore, addressing the above, in conjunction with the PRP, resulted in initial positive clinical tests all becoming negative, and a symptom free patient who could return to her chosen sport.

Competing Interests: No competing interests were disclosed.

Reviewer Report 08 January 2013

https://doi.org/10.5256/f1000research.403.r603

(c) 2013 Van Rijen X. This is an open access peer review report distributed under the terms of the Creative Commons Attribution License, which permits unrestricted use, distribution, and reproduction in any medium, provided the original work is properly cited. 


\section{Xander Van Rijen}

Joondalup Health Campus, Joondalup, WA, Australia

I believe the article to be a good contribution to support continued clinical study of $P R P$ in labral tears. As a comment to the author, I would seek clarification on the validity of the combinations of shoulder tests used (according to Netter's Orthopaedic Clinical Examination, combinations of tests are only moderately helpful in identifying labral tears).

Competing Interests: No competing interests were disclosed.

\section{I confirm that I have read this submission and believe that I have an appropriate level of expertise to confirm that it is of an acceptable scientific standard.}

Author Response 20 Mar 2013

Robert Vander Kraats, Next Generation Physiotherapy, Greenwood, Australia

Lyndsay Somerville, in her 2012 doctorate, and later published in 2013 in the BMC Musculoskeletal Disorders Journal, makes an interesting point suggesting that the sensitivity of SLAP tests in isolation are poor. For example, Somerville reports that amongst other tests, the sensitivity of Speed's Test is $24.6 \%$, Biceps Load I is $10.3 \%$ and Resisted Supination ER is $14.3 \%$. Based on the low scores, Somerville proposes that through clinical reasoning considering several tests is likely to paint a better picture than simply one poorly sensitive test in isolation.

Competing Interests: none

Reviewer Report 08 January 2013

https://doi.org/10.5256/f1000research.403.r602

(C) 2013 Maffulli N. This is an open access peer review report distributed under the terms of the Creative Commons Attribution License, which permits unrestricted use, distribution, and reproduction in any medium, provided the original work is properly cited.

\section{Nicola Maffulli}

Barts and the London School of Medicine and Dentistry, Queen Mary, University of London, London, UK

This is a case report (two cases) reporting the application of an autologous blood product (PRP) in Glenoid Labral Tear. The recent evidence suggests that PRP, despite the great hype, is of no benefit in the management of musculoskeletal conditions. I have no doubts that these two patients have done well, but, without a control group, this manuscript only perpetuates a myth. In this respect, the authors have chosen to ignore the meta-analysis published in by Sheth et al. 2012, and to jump on the bandwagon. In this respect, therefore, what they report is at best dubious science. 
Competing Interests: No competing interests were disclosed.

I confirm that I have read this submission and believe that I have an appropriate level of expertise to state that I do not consider it to be of an acceptable scientific standard, for reasons outlined above.

\section{Author Response 20 Mar 2013}

Robert Vander Kraats, Next Generation Physiotherapy, Greenwood, Australia

The authors are well aware of the limitation of a case report with respect to no control group. We in fact stated this in the case report and the need for further research. It is however hard to compare our paper with other papers directly as this is the first published paper on PRP into glenoid labral tears. Sheth et al.'s 2012 meta-analysis doesn't discredit PRP in isolation, it rather states due to the lack of standardisation of study protocols, platelet-separation techniques, and outcome measures there is uncertainty. Therefore, in a situation like this, one needs to delve into further research before discrediting ones paper and suggesting it it of "dubious science".

For example, Peerbooms et al. (2010) in his double-blinded randomised controlled trial with a 1 year follow up found a clinically significant reduction in pain and an improvement in function in patients with lateral epicondylitis when PRP was used compared to corticosteriods. Further, Taylor et al. (2011) in his systematic review concluded that PRP has advantages for tendon and ligament injuries, by way of promoting a faster recovery, a reduction in recurrence, and with no adverse reactions described. Therefore, our case report, in conjunction with the above mentioned research, certainly repudiates that PRP is "of no benefit in the management of musculoskeletal conditions" as you suggest.

Competing Interests: none 
The benefits of publishing with F1000Research:

- Your article is published within days, with no editorial bias

- You can publish traditional articles, null/negative results, case reports, data notes and more

- The peer review process is transparent and collaborative

- Your article is indexed in PubMed after passing peer review

- Dedicated customer support at every stage

For pre-submission enquiries, contact research@f1000.com 